\title{
Binary phase diagrams of lead(II) n-alkanoates and n-alkanoic acids
}

\author{
J.A.R.Cheda*, F. Ortega, A. Sánchez Arenas and A. Cosio. \\ Dpto. Quimica Fisica, Fac. C. Quimicas, \\ Universidad Complutense, 28040 Madrid, spain. \\ M. Fernández-García and F. Fernández-Martín. \\ Instituto del Frío (CSIC), 28040 Madrid, Spain. \\ M.V. Roux and C. Turrión. \\ Instituto Rocasolano (CSIC), 28006 Madrid, Spain.
}

\begin{abstract}
During the last decades there has been a renewed interest in the study of salts with organic anion and /or cation, not only as pure substances but also their mixtures with any kind of solvents. Special attention will be given in this report to the mixtures of organic salts with organic acids. It is well known that the association of alkali alkanoates ("soaps") and alkanoic acids into a crystalline molecular complexes ("acid soaps") of a given stoichiometry ( $1: 1,2: 1,3: 2$, etc.) generally melt incongruently. Besides these peritectic points, a lyotropic mesomorphism is also frequently found. The thallium(I) alkanoates and some acid + salt phase diagrams have been investigated recently, showing formation of only a 1:1 molecular complex, which melts incongruently, and the appearance of lyotropism. On replacing thallium(I) by lead(II), the binary phase diagram shows completely different features. No molecular association between the acid and the salt is found in the solid state. The complete phase diagram resembles those of the surfactants in water. A Krafft-like point is found, in which the solubility of the salt increases dramatically pointing to the formation of micellar aggregates. The presence of thermotropic mesomorphism corresponds to lyotropism in that region of the phase diagram.
\end{abstract}

\section{INTRODUCTION}

During the last decades there has been a great interest in research on salts with organic anion and/or cation, as it can be seen in the valuable reviews on pure salts and mixtures like the ones published by Franzosini and Sanesi (ref. 1 and 2), Gordon (ref. 3) and Lind (ref. $4)$.

One of the interests of these systems is the fact that by simple experimental changes of the salt structure -either the structure of organic ion and/or the size and charge of the counterion- differences in physical propierties can be found. These allow to stablish structure-property correlations that are of scientific interest and may have important technological applications.

In the case of mixtures of these salts, mainly with water, but also with organic solvents (especially with organic acids), we are looking at important fields since the different kind of interactions observed by the systems are of interest in also science and industry. 
PURE ORGANIC SALTS

It is important to point out the step-melting process of the pure salts that leads to the appearance of polymorphism and thermotropic mesomorphism (plastic and liquid crystals). This process has been generaliy found on many series of cationic or anionic organic salts containing alkyl chains. Good examples of this are the thallium(I) (ref. 5 and 6) and lead(II) (ref. 7) n-alkanoates series. Figures 1 and 2 show schematically the thermal behaviour of these two series of compounds (temperatures of transitions vs total number of carbons). These series behave similarly to the alkali alkanoate ones (ref. 1), although the polymorphic pattern is less rich in the case of lead(II) in comparison with the other series (thallium(I) and alkali). In the lead(II) series the temperature range of liquid crystal existence is narrower than in the other ones and reduced to less members of the series (it is only present until the dodecanoate). It is noteworthy to point out that the mesomorphism of lead(II) salts together with the discotic mesophase presented by $\mathrm{Cu}$ (II) and $R h$ (II) (ref. 8) are in the best of our knowledge, the only known cases of thermotropic mesomorphism occurring on divalent cation organic salts.

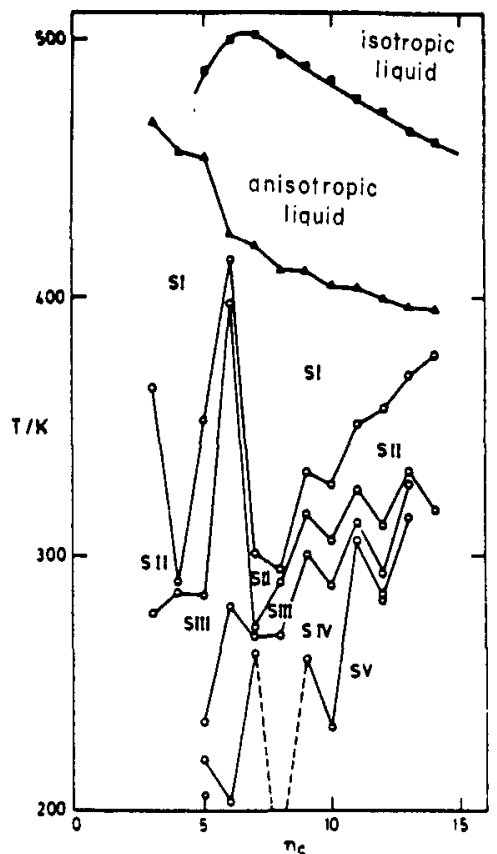

F1g. 1. Transition temperatures vs total number of carbons for the thallium(I) n-alkanoates.

\section{MIXTURES}

Alkali n-alkanoates are typical surfactant molecules. A surfactant, amphiphilic or tensioactive, contains coexisting in the molecule, both a lyophobic group which has little or no attraction for the solvent, and a lyophilic group which has a strong attraction for the same. When in solution, segregation of the amphiphile from the solvent leads to a very rich self-assembling behaviour.

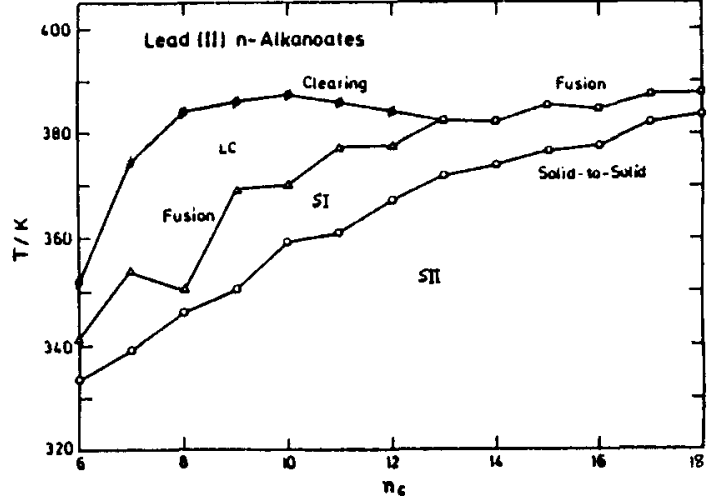

F1g. 2. Transition temperatures vs total number of carbons for the lead(II) n-alkanoates.

A great deal of work has been devoted to the study of these systems, mainly with water (ref. 9). A typical water + surfactant phase diagram presents a region of micellar solution above what is called the krafft point, frequently at very low concentration (critical micellar concentration) and temperature (Krafft temperature). Another typical aspect of these phase diagrams is the appearance of lyotropic mesomorphism when increasing the concentration of surfactant, usually 
in this order: hexagonal or nematic, planar or smectic and cubic, connecting with the thermotropic mesomorphism, if existing, of the pure surfactant. The sodium dodecylsulfate + water (ref. 10) and sodium laurate + water (ref. 11) are examples of the most representative and better studied systems.

The organic solvent + surfactant binary phase diagrams have been much less studied. only partial solubility data are available (ref. 12 and 13). An exception is the case of alkali alkanoates + carboxylic acid, probably due to the technological applications of these systems in cosmetic and detergent industries. It was early recognized (ref. 14-18) the association of alkali alkanoates with alkanoic acids into a crystalline hydrogen bonded molecular complexes, called "acid soaps", with a given stoichiometry (1:1, 2:1, 3:1, etc.) which generally melt incongruently.

In figures 3 (from ref. 14) and 4 (from ref. 15), two of these typical salt + acid phase diagrams are presented, showing two different kinds of regions. One corresponds to the one-phase regions (isotropic liquid, mesomorphic and, in one of the cases, mixed crystals phase). The other type is the two-separated-phase regions. The presence of thermotropic mesomorphism in the pure salt corresponds always to lyotropism in that region of the phase diagram.

At this point it is interesting to mention the studies of Ekwall and Mandell (ref.19) on ternary phase diagrams of sodium alkanoate + alkanoic acid + water systems where the important role the acid plays on the solubility of the salt in water as the temperature increases is clearly demonstrated.

Some thallium(I) n-alkanoate + n-alkanoic acid systems have been investigated (ref. 20 and 21). Their phase diagrams resemble greatly those of the alkali salts, but with the formation of only a single 1:1 molecular complex. Lyotropism is also observed near the thermotropic liquid crystal of the pure salt. The study of the analogous systems is in progress, but we already know that all of them from thallium(I) propanate + propanoic acid to thallium(I) $n$-tetradecanoate $+n$-tetradecanoic acid present the same feature with only one molecular association (ref. 22).

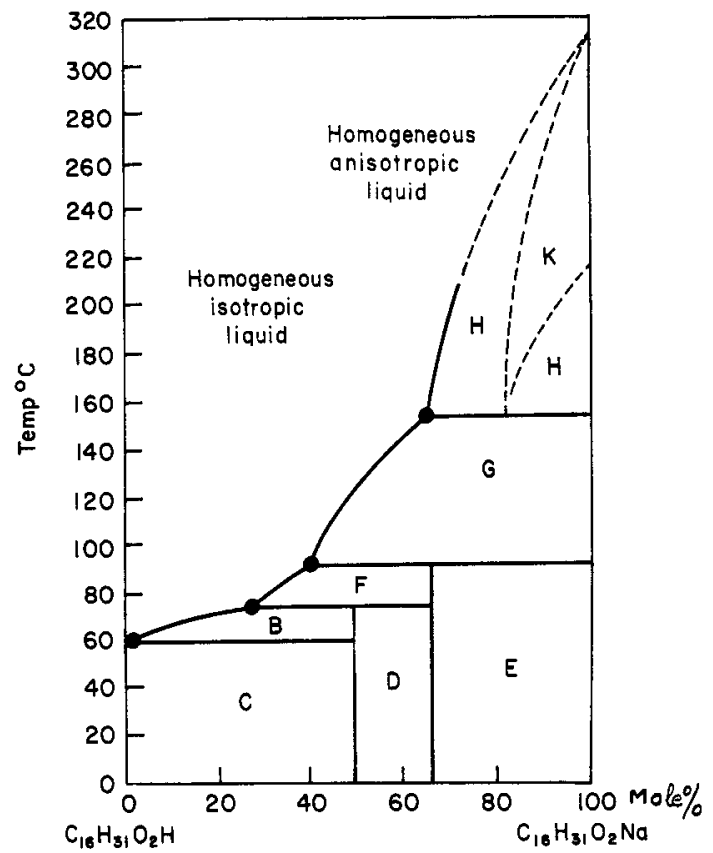

Fig. 3. Phase diagram of sodium palmitate + palmitic acid (taken from ref. 14).

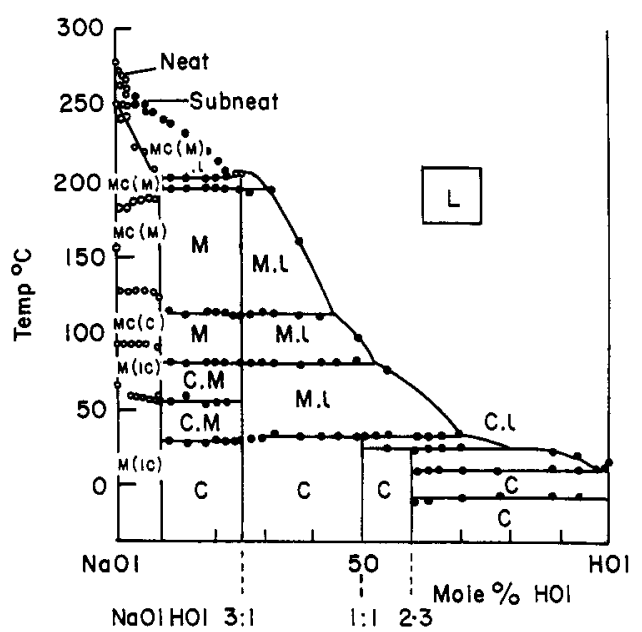

Fig. 4. Phase diagran of sodium oleate + ole1c acid (taken from ref. 15 ). 


\section{LEAD(II) ALKANOATE-ALKANOIC ACID SYSTEMS}

When replacing thallium(I) by lead(II), the binary phase diagram change into a completely different shape. The $T-x$ plots for the thallium(I) (ref. 20) and the lead(II) (ref. 7) n-tetradecanoate + n-tetradecanoic acid are shown in figure 5, (a) and (b), respectively, showing striking differences.
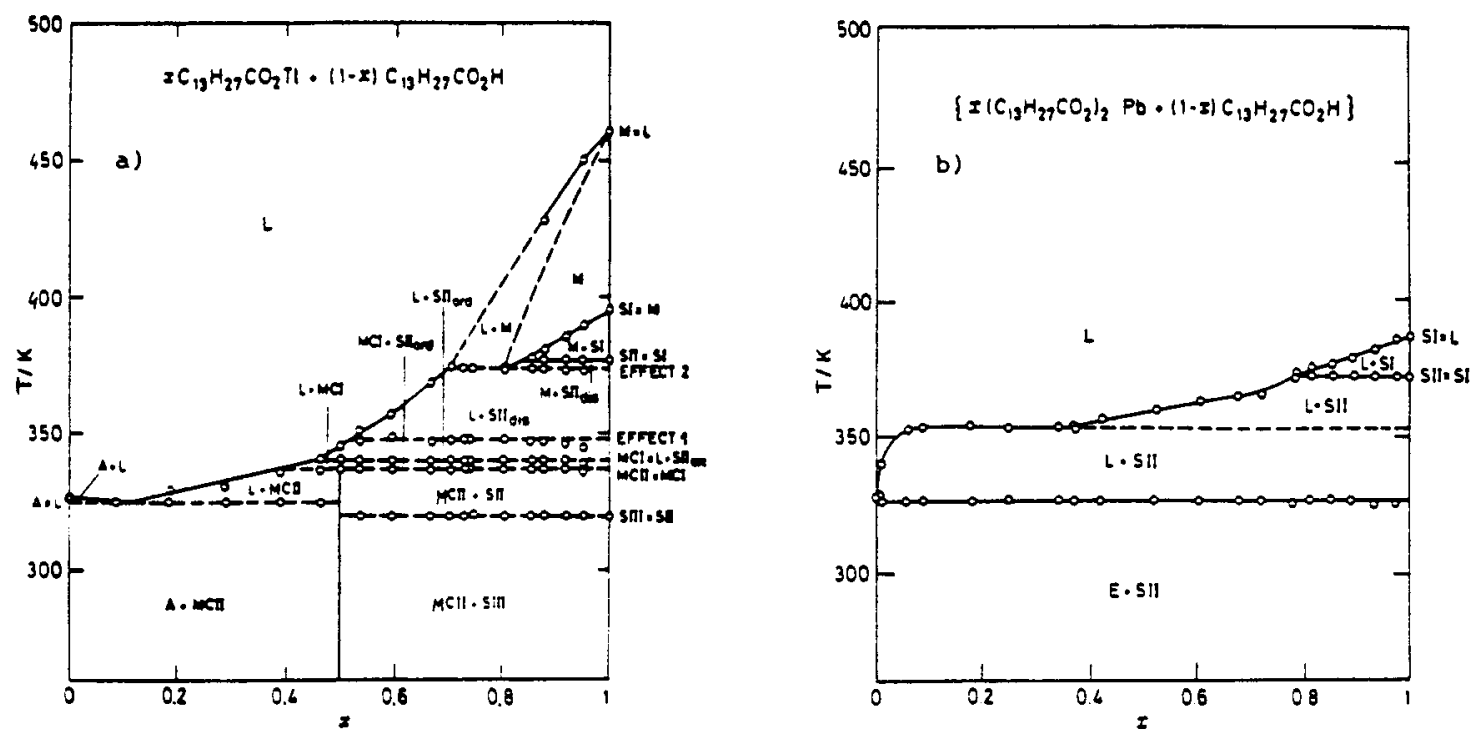

Fig. 5. Phase diagram of metal ion n-tetradecanoate + n-tetradecanoic acid: a) thallium(I): b) lead(II).

In the case of lead(II), no molecular assotiation (acid soap), neither congruent nor incongruent melting is found in the solid state. This is confirmed by the presence of a eutectic which is an invariant through out the whole range of composition. This eutectic point appears at an abnormally low salt molar fraction, this being in agreement with the very low depression of the melting point of the acid. This is reflected in the eutectic temperatures through the whole range of composition which are very close to the pure acid melting point, as it can be clearly seen in figure 6 , where direct observations were done to determine the eutectic point.

Figure 7 (a) and (b) corresponds to the phase diagrams of lead(II) n-tridecanoate and n-decanoate, respectively, with the corresponding n-alkanoic acids. The lead(II) $n$-decanoate is the only member of the lead(II) n-alkanoates series presenting thermotropic liquid crystal phase that corresponds in the phase diagram to the appearance of lyotropism. This part of the mesomorphic region is similar to the one found in alkali and thallium

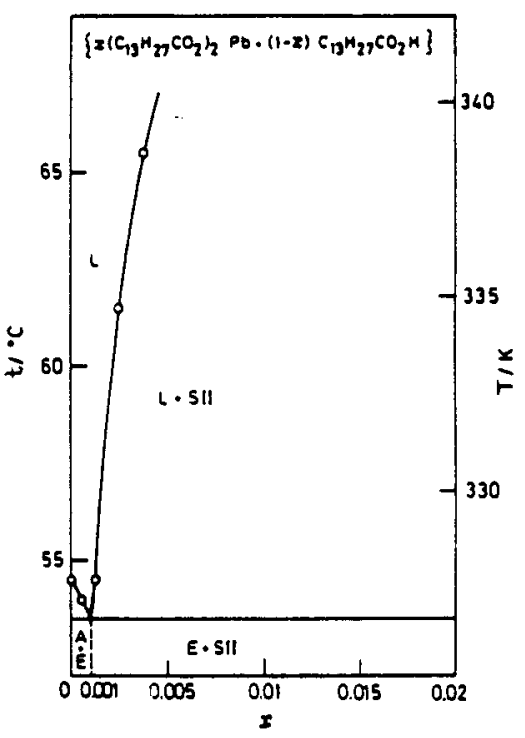

F1g. 6. Eutectic point region corresponding to figure $5 \mathrm{~b}$. 
phase diagrams. We know of only one other system reported in the literature and corresponds to the lead(II) $n$-dodecanoate $+n$-dodecanoic acid (ref. 23). The results corresponding to this phase diagram are in general agreement with those that we report above, but the presence of a eutectic point is ignored, confusing it with a regular melting point of the pure acid, leading to a misinterpretation of the low region of the phase diagram.

The lead(II) n-alkanoate + n-alkanoic acid phase diagrams resemble those of surfactants in water in the sense that the solubility of the salt increases dramatically above a given value of concentration. That may indicate a Krafft-like behaviour with formation on the isotropic liquid of micellar aggregates. At a mole fraction of about $1 / 3$ -corresponding equimolar amounts of chains bonded to carboxylate and carboxylic head groups- a change of the slope of solubility occurs in all the systems, pointing to a different kind of aggregation in the liquid state. Although a few systems (four) are available to get general conclusions, some trends can be established. The Krafft temperatures follow a smooth increase with the total number of carbon atoms of alkyl chains. The critical micellar concentrations at the Krafft point are so low in all the cases, ranging approximately $0.050-0.015$ salt molar fraction, that no general pattern can be deduced.

Martin and Pink (ref 12) on a very early work studied the solubilities of divalent metal n-alkanoates in organic solvents. They reported the formation of micelles, by a mechanism which consider the balance between the solubilising power of the hydrocarbon chains and the attractive forces between the dipoles present in the head of the surfactant. Our systems fit with this interpretation, if we
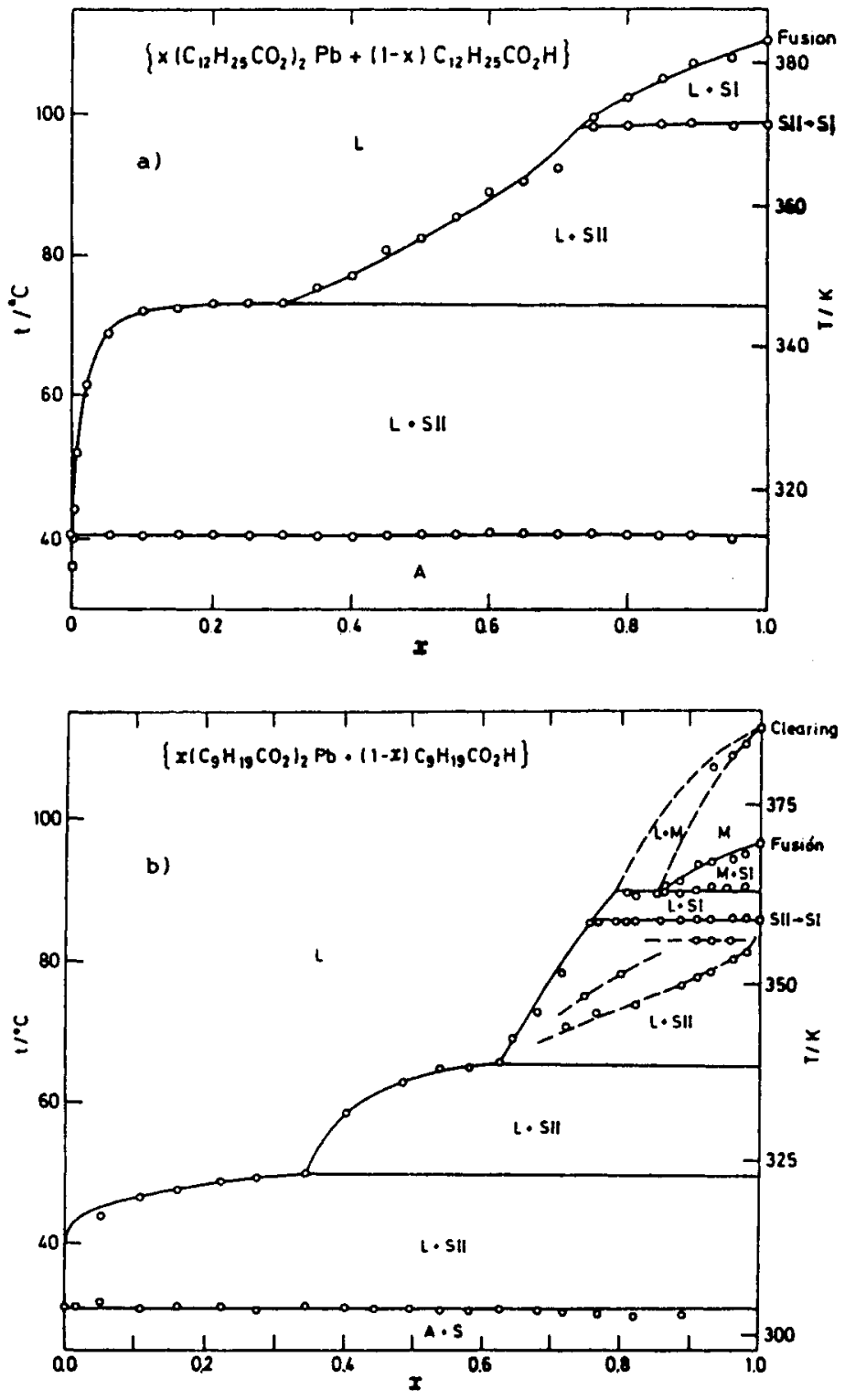

F1g. 7. Phase diagram of the $\mathrm{Pb}(\mathrm{II})$ series:

a) n-tridecanoate + n-tridecanolc acid;

b) $n$-decanoate $+n$-decanolc acid. 
consider the acid as an organic polar solvent. The shape of the phase diagram can be considered by itself as a strong indication of the salt solubilitation into the acid by means of an aggregation process. Nevertheless, other experimental techniques were used. The very low electrical conductivity (less than $1 \mu \mathrm{s} \cdot \mathrm{cm}^{-1}$ ) determined on these systems at high temperature strongly support the absence of free ions in the solution. On the other hand, we have also carried out viscosity measurements on the system lead(II) n-decanoate $+n$-decanoic acid at $60^{\circ} \mathrm{C}$ (figure 8 ). The change in the slope of the kinematic viscosity vs composition curve (figure 8(a)), or the minimum in the especific relative kinematic viscosity vs composition curve (figure $8(b)$ ) can be considered as another strong indication of micellar formation, the critical micellar concentration being represented by an arrow in both plots.

We have also performed studies on the solubility of both thallium(I) and lead(II) salts in water, looking for the possible formation of micellar aggregates. In the case of the thallium(I) homologous, no micellar aggregation was observed from pentanoate downwards in chain length, while it was clearly observed in the next three members (hexanoate to octanoate, with CMC decreasing as increases the chain length) but at relatively high Krafft temperatures ranging above $60^{\circ} \mathrm{C}$. In the $\mathrm{Pb}(\mathrm{II})$ salts family, however, it was not possible to reach the corresponding critical micellar concentration on any homologous member even at the boiling point of water. These facts have also been confirmed by experiments on electrical conductivity and vapour pressure osmometry (ref. 7).
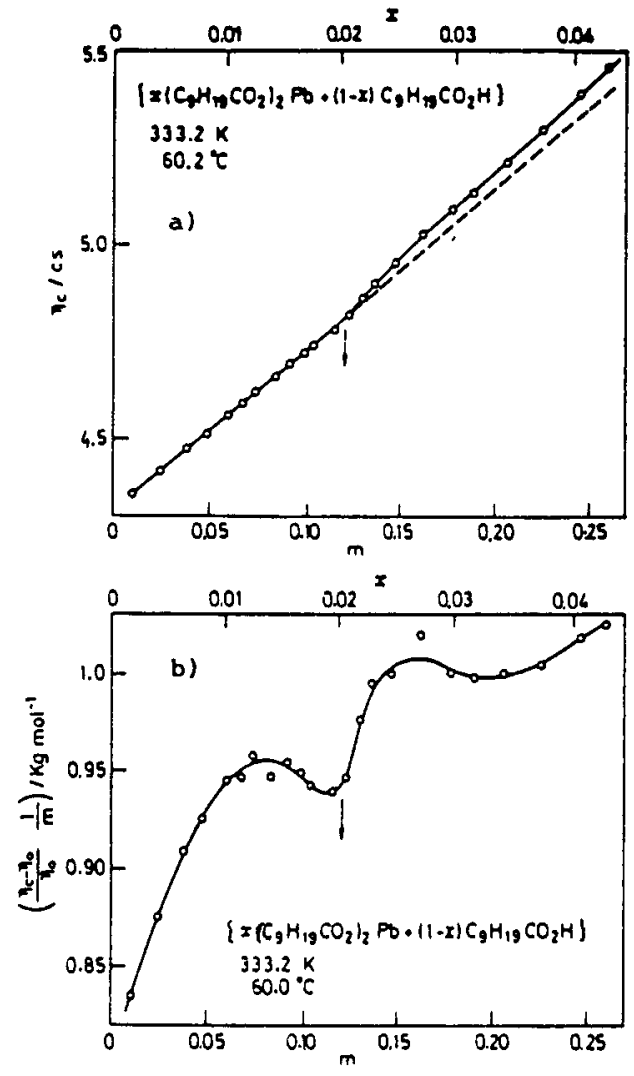

Fig. 8. Viscosity measurements on $\mathrm{Pb}$ (II) n-decanoate $n$-decanolc acid: a) kinematic $\nabla$ iscosity:

b) specific molar viscosity.

\section{REFERENCES}

1. P. Franzosini and M. Sanesi, Thermodynamic and Transport Properties of organic Salts. Pergamon Press, London (1980).

2. P. Franzosini, Molten Alkali Metal AlKanoates Vol 33 in Solubility Data Series. ed. by A.S.Kester, Pergamon Press, New York (1988).

3. J.E. Gordon, Applications of Fused Salts in organic Chemistry in Techniques and Methods of organic and organometallic Chemistry. 1 ed. by D.B. Denuer M. Dekker, New York, 51-188 (1969).

4. J.E. Lind, Molten organic Salts-Physical Properties in Advances in Molten Salt Chemistry Vol. 2 . Ed. by J. Braunstein, G. Mamantov and G.P. Smith, Plenum press, New York, 1-26 (1973).

5. A.K. Labban, F.L. López de la Fuente, J.A.R. Cheda, E.F. Westrum Jr. and F. Fernández-Martín, J. Chem. Thermodinamics 21 375-384 (1989). 
6. F.L. López de la Fuente, Propiedades Termofisicas y Transiciones de Fase de n-Alcanoatos de Talio(I), Ph. D. Thesis, Facultad de Ciencias Quimicas, Universidad Compiutense, Madrid (1989).

7. Unpublished results.

8. A.M. Giroud-Godquin, J.C. Marchon, D. Guillon and A. Skoulios, J. Phys. Lett. 45, L681 (1984) and J. Phys. Chem. 90, 5502 (1986).

9. G.J.T. Tiddy, Surfactant-water liquid crystal phases. Phy. Rep. 57, $1-46(1980)$.

10. P. Kekicheff, C. Grabielle-Madelmont and M. Ollivon, J. Colloid and Interface Science 131, 112-132 (1989).

11. C. Madelmont and R. Perron, Bull Soc. Chim. France, 425 (1974).

12. E.P. Martin and R.C. Pink, J. Chem. SoC. 1750-1755 (1948).

13. M.S. Akanni, H.D. Burrows, H.A. Ellis, D.N. Asongwed, H.B. Babalola and P.O. Ojo, J. Chem. Tech. Biotechnol. 34A 127-135 (1984).

14. J.W. McBain, A. Stewart, J. Chem. Soc. 924 (1933).

15. H.W. Brouwer, H.I. Spier, Procedings of the Third ICTA. 3, 131-144 (1971)

16. T. Meisel, K. Seybold, J. Roth, Cs. Mélykuti, J. Therm. Anal. 10-419 (1976).

17. H.C. Kung, E.D. Goddard, J. Colloid Interface Sci. 29-242 (1969).

18. E.D. Goddard, S. Goldwasser, G. Golikeri, H.C. Kung, Adv. Chem. Ser. 67 (1968).

19. P. Ekwall, L. L. Mandell and K. Fontell, colloid $\underline{\&}$ Polimer Sci. 264 $542-551(1986)$.

20. M. Fernandez-García, Diagrama de Fases del sistema Binario Acido n-Heptanoico y n-Heptanoato de Talio(I), Master Degree Dissertation Fac. C. Quimicas. Univ. Complutense. Madrid (1989).

21. J.A.R. Cheda, M. Fernández-Garcia, P. Ferloni, F. Fernández-Martín, J. Chem. Thermodynamics 23 495-502 (1991).

22. F. Fernández-Martín, M. Fernández-Garcia and J.A.R. Cheda, Proceedings of the XII Convegno Nazionale di Calorimetria ed Analisi Termica, Bari (Italy), December (1990).

23. S.O. Adeosum and M.S. Akanni, Thermochimica Acta 27 133-140 (1978). 